\title{
Educação, Corporeidade e Espacialidade: uma perspectiva geográfica sobre os projetos sociais de dança em Fortaleza/CE
}

\author{
Education, Corporeity and Spatiality: a geographic perspective on the social projects \\ of dance in Fortaleza/CE
}

\begin{abstract}
Educación, Corporeidad y Espacialidad: una perspectiva geográfica sobre los proyectos sociales de danza en Fortaleza/CE
\end{abstract}

\author{
Jéssica Mesquita Barbosa ${ }^{1}$ \\ Marcos da Silva Rocha ${ }^{2}$ \\ Christian Dennys Monteiro de Oliveira ${ }^{3}$
}

\begin{abstract}
RESUMO: No seio da dinâmica socioespacial periférica da cidade de Fortaleza, este artigo busca analisar os projetos sociais de dança na capital cearense realizando uma apreciação empírica e uma reflexão teórica dos mesmos. Visa-se também visibilizar tais instituições de Fortaleza no sentido de expor os papeis e práticas sociais realizadas. Mais precisamente, debatemos qual o papel destas organizações na vida de crianças e adolescentes que vivem em situação de vulnerabilidade socioeconômica, fazendo um paralelo com o processo de urbanização da cidade. Desta feita, apoiando-se em uma base fenomenológica e geográfica para a construção dos caminhos metodológicos, utilizam-se entrevistas semiestruturadas, trabalhos de campo e a consulta e análise de notícias e textos jornalísticos como a principal tríade metodológica da pesquisa. Discute-se também como e porque ocorre o processo de marginalização social na cidade de Fortaleza e apresenta-se, por fim, como a arte da dança pode auxiliar crianças e jovens na busca pela construção de uma existência digna e significativa através do exercício da cidadania.
\end{abstract}

PALAVRAS-CHAVE: Periferia. Dança. Cidadania.

\begin{abstract}
Within the socio-spatial dynamics of the city of Fortaleza, this article seeks to analyze the social projects of dance in the capital of Ceará, making an empirical appreciation and a theoretical reflection of them. It is also intended to make these Fortaleza institutions visible in the sense of exposing the roles and social practices carried out. More precisely, it is discussed the role of these organization in the lives of children and adolescents living in situations of socioeconomic vulnerability, paralleling the process of urbanization of the city. Based on a phenomenological and geographical basis for the construction of methodological paths, semi-structured interviews, fieldwork and the consultation and analysis of news and journalistic texts are used as the main methodological triad of

\footnotetext{
1 Universidade Estadual do Ceará. Avenida Doutor Silas Munguba, 1700 - Campus do Itaperi, 60741-000, Fortaleza - CE. E-mail: jessicambarbosa0@gmail.com.

2 Secretaria Municipal de Educação de Fortaleza. Avenida Desembargador Moreira, 2875 - Dionísio Torres, 60170-002, Fortaleza - CE. E-mail: marcoss.rocha@hotmail.com.

${ }^{3}$ Universidade Federal do Ceará (UFC). Av. Humberto Monte, s/n - Campus do Pici, 60440-593, Fortaleza - CE. E-mail: cdennys@gmail.com.
} 
the research. It also discusses how and why the process of social marginalization occurs in the city of Fortaleza, and presents, finally, how the art of dance can help children and young people in the search for a dignified and meaningful existence through the exercise of citizenship.

KEYWORDS: Periphery. Dance. Citizenship.

RESUMEN: En el seno de la dinámica socioespacial periférica de la ciudad de Fortaleza, este artículo busca analizar los proyectos sociales de danza en la capital del Ceará, realizando una apreciación empírica y una reflexión teórica de los mismos. Se pretende también visibilizar tales instituciones de Fortaleza en el sentido de exponer los papeles y prácticas sociales realizadas. Más concretamente, se debate cuál es el papel de estas organizaciones en la vida de niños y adolescentes que viven en situación de vulnerabilidad socioeconómica, haciendo un paralelo con el proceso de urbanización de la ciudad. De esta vez, apoyándose en una base fenomenológica y geográfica para la construcción de los caminos metodológicos se utilizan entrevistas semiestructuradas, trabajos de campo y la consulta y análisis de noticias y textos periodísticos como la principal tríada metodológica de la investigación. Se discute también cómo y por qué ocurre el proceso de marginación social en la ciudad de Fortaleza y se presenta, por fin, cómo el arte de la danza puede auxiliar a niños y jóvenes en la búsqueda por la construcción de una existencia digna y significativa a través del ejercicio de la ciudadanía.

PALABRAS-CLAVE: Periferia. Danza. Ciudadanía

\section{INTRODUÇÃO}

"Diferente é que a gente dança e lá a gente estuda com livros. Gosto mais daqui". Essa é a fala da Kimberley, de nove anos, aluna do Instituto Katiana Pena, em resposta à pergunta "O que você acha diferente entre aqui e a sua escola?". Podemos observar nessa fala como os projetos sociais de dança em Fortaleza funcionam como uma alternativa artística, educacional e de diversão para crianças e jovens da periferia de Fortaleza. Estas crianças vivem em um contexto de marginalização urbana e social, longe de serviços básicos e infraestrutura. Também vivem as desigualdades sociais latentes em que a escola está inserida, tornando-se, esta, reflexo dessas realidades.

Apresentaremos, no presente trabalho, o papel social de projetos sociais de dança, sua irradiação enquanto equipamento cultural e também como um potencial método de aprendizagem de espacialidade e corporeidade, além do seu papel em ir de confronto à realidade de violência. Qual a relação entre dança, geografia, educação e cultura? Podemos fazer esse paralelo discutindo o papel da dança em diferentes sociedades, como ela é usada para responder sobre a origem do universo, como ela faz parte dos sistemas culturais e educativos, além de como ela é utilizada para criar novos universos dentro de uma realidade urbana que oferece condições limitadas de desenvolvimento cultural, social e educacional.

A criação do mundo já é uma ação geográfica e dependendo da escala em que se fala e do sujeito, a palavra "mundo" pode ter diversas interpretações. Pode se constituir como 
planeta Terra ou o desenvolvimento de um cotidiano de um bairro. A geografia traduz-se como o estudo do espaço enquanto dimensão viva e fundante das relações sociais, em diversas escalas. Dessa forma, somos levados a pensar: como nossas ações tem o poder de transformar o espaço? Qual nosso papel social e cultural no espaço em que vivemos?

Importante lembrar que o processo de formação em geografia surge na educação informal ou formal, a partir do reconhecimento do ser como dinamizador do espaço, do seu papel na sociedade e potencializado na escola, através de livros didáticos e o cotidiano escolar. Levando em consideração esses aspectos, é importante nos perguntarmos: qual a responsabilidade da educação na construção de uma sociedade igualitária? Em uma sociedade que não oferece as mesmas condições de sobrevivência, por questões de desigualdade social, há muitos questionamentos para a geografia e a educação, principalmente se falarmos no contexto das áreas mais periféricas da cidade de Fortaleza. Estes são alguns dos questionamentos que pretendemos responder a partir de nossa metodologia.

\section{Pas de Deux Metodológico: Geografia e Fenomenologia}

Uma metodologia de base fenomenológica ajuda nos caminhos dessa pesquisa, pois investigaremos a espacialidades, percepções dos sujeitos e a influência dos projetos sociais de dança. Para Silva, Lopes e Diniz (2008) esse método filosófico desvela a cotidianidade do mundo do ser onde a experiência se passa, e transparece na descrição de suas vivências de suas relações viscerais com o mundo em que vivem (DARDEL, 2015). Portanto, buscamos compreender a geografia dos projetos sociais de dança em Fortaleza a partir da percepção dos atores envolvidos por eles.

Buscamos então, considerando as discussões apresentadas, construir uma associação entre o espaço periféricos urbanos da metrópole fortalezense e seus projetos sociais. Tendo como foco principal os projetos sociais de dança, procuramos encarar as vivências e experiências dos sujeitos a partir de entrevistas semiestruturas com três grupos principais: a) estudantes dos projetos; b) gestores e professores; e c) comunidade do entorno.

Desta forma, os trabalhos de campo constituem importante etapa metodológica pois, além das entrevistas, estes momentos também nos dão a oportunidade de imergir na realidade investigada, experimentar a realidade destes bairros periféricos, além de realizar registros fotográficos e coleta de dados cartográficos. Além disso, é importante estudar o alcance de uma ação desenvolvida através do espaço que a mídia jornalística dá para ela. Sendo assim, utilizamos também notícias veiculadas sobre os projetos de referência do estudo. 
Este artigo divide-se em cinco seções principais contando com esta introdução. $\mathrm{Na}$ seção dois, debateremos sobre os aspectos cosmológicos e filosóficos da dança a partir do hinduísmo para construir um paralelo com a criação de diversos mundos que existem dentro de uma só cidade. Ainda neste tópico apresentamos uma discussão sobre corporeidade, sendo ela o início da comunicação do ser humano com o mundo e, a partir disso, o início da construção de relações corpo-espaciais. Na seção seguinte, elaboramos um panorama sobre Fortaleza partindo de seus índices de vulnerabilidade social para contextualizar o papel das organizações da sociedade civil, dando enfoque nos projetos de dança em Fortaleza. A seção quatro aborda o universo simbólico da percepção dos sujeitos que participam dos projetos sociais e mostra como a dança é um vetor de resistência à vulnerabilidade social.

\section{DA COSMOLOGIA DA DANÇA À CORPOREIDADE EDUCATIVA NOS SUJEITOS}

Dependendo de cada cultura ou civilização, há diferentes formas de se acreditar sobre como surgiu o mundo. Há os que se baseiam nas forças da natureza, em escritos sagrados e em mitos passados de geração em geração. Cada história se desenvolve a partir das necessidades místicas e de respostas de cada povo. O ser humano sempre foi e é inquieto e curioso em relação ao seu surgimento, seu papel no espaço, e em tempos de pré-escrita e experiências sensoriais puramente empiristas, pensar e imaginar para além do que os olhos enxergam é forma de descrever e pensar o mundo desde sua gênese, formando, assim, diversas formas de se relacionar com a natureza. Para Dardel (2007, p. 47):

Essas Geografias se ligam cada uma delas a certa concepção global do mundo, uma inquietude, central, uma luta efetiva contra o fundo escuro da natureza circundante. É dizer que essa história só faz sentido se compreendermos que a Terra não é um dado bruto a medirmos como ele "se dá", mas que sempre transita entre o Homem e a Terra uma interpretação, uma estrutura e um "horizonte" de mundo, um esclarecimento que mostra um real no real, uma "base" a partir da qual ele se desenvolve.

Um dos exemplos da ligação entre geografia e mitologia está na religião Hinduísta, em que o deus Shiva, integrante da trindade hindu, é o Rei dos Dançarinos. "Representa o eterno movimento do Universo, que foi impulsionado pelo ritmo e o tambor da dança" (LOPES; BARROS, 2006, p. 52). Assemelha-se aos ciclos naturais de vida, morte e transformações.

Assim como Shiva cria o mundo através de seus movimentos, estudaremos aqui como os pertencentes aos projetos sociais criam seus próprios mundos, e como eles dançam entre palácios incendiados por tantos problemas socioeconômicos que os cercam. 


\section{Corporeidade e Sociedade}

O sujeito dançante surge a partir do momento em que um corpo se movimenta, seja por distração, por um contágio de alegria, como uma forma de sedução, ou de exercício físico, seja por ser uma profissão, seja como afirmação de uma cultura em grupo ou um convite romântico para dançar a dois.

Quando se fala em corporeidade, é importante atentar ao filósofo e coreógrafo Rudolf Laban, que no século XX formula um sistema de experimentação e análise de movimento de forma poética, que segundo Miranda (2008, p. 17) "[...] onde o corpo e visto como parte de uma relação estrutural em movimento, que inclui Corpo, Esforço, Forma e Espaço, categorias interacionadas que se informam mútua e continuamente". $\mathrm{Na}$ contemporaneidade, Queiroz Filho (2018, p. 44) nos traz o conceito de carto-corpo-coreografia, $O$ "[...] corpo que desacostuma o sensível e faz do si mesmo uma cartografia a ser, simultaneamente, descoberta e inventada".

Nesse sentido, o corpo seria o início da comunicação do homem com o mundo exterior, bem como o princípio de uma cultura e seu processo evolutivo. A partir disso, também podemos falar de um processo de construção de uma linguagem que tem como premissa básica o movimento corporal. Cada tipo de movimentação diferente, combinado com outros elementos como vestimenta ou adereços e músicas, podem originar diversas manifestações culturais diferentes, que muitas vezes também são classificadas como folclóricas.

O sentido da dança é a própria experiência humana. Por isso, só é possível compreender esse sentido na experiência, seja na experiência estética, a experiência da beleza ou ainda nas experiências educacionais, recreativas ou ritualísticas (BARRETO, 2004, p. 76).

Como bem lembrado ainda por Miranda (2008), o corpo tem diversas formas de ser estudado. Se no âmbito mais antropológico, são estudadas suas individualidades de acordo com o seu grupo social; se na ótica psicanalítica, o corpo é fator discursivo e imagético. Se pensarmos em um âmbito geográfico, é importante lembrar de Santos (1988, p. 21), em que "[...] tanto a paisagem quanto o espaço resultam de movimentos superficiais e de fundo da sociedade, uma realidade de funcionamento unitário, um mosaico de relações, de formas, funções e sentidos". Ou seja, tudo o que é produzido em um espaço tem como premissa inicial um corpo que se movimenta e, em consequência, faz mover vários corpos, seja em um simples ato de pegar um ônibus ou participar de um festival de danças juninas no nordeste brasileiro. 


\title{
Dança como Processo Educativo-formativo
}

Apesar da arte está presente na vida dos seres humanos desde sempre, ela só se faz presente como atividade essencial na educação brasileira na segunda metade século $X X$, quando psicopedagogos, filósofos, antropólogos e críticos de arte passaram a classificar a arte da criança como manifestação espontânea e auto expressiva, utilizando seu potencial criador como experimentação artística e, consequentemente, aliada ao desenvolvimento intelectual e físico. Foi incluída na Lei de Diretrizes e Bases da Educação Nacional de 1971 como atividade curricular, podendo consistir em educação musical, artes plásticas e desenho, dentre outras (BRASIL, 1998). O problema é que não havia cursos de capacitação para os professores, pois eles eram formados para ensinar apenas o que se entendia como ensino regular, nem ao menos sendo artistas. Em outra tentativa, foi criada a lei de 13.278/2016 (BRASIL, 1996), que altera a Lei de Diretrizes e Bases da Educação Nacional, estabelecendo o prazo de cinco anos para que as escolas regulares incluíssem dança teatro e música em vários níveis de educação. Isso seria enriquecedor para o desenvolvimento cognitivo e psicomotor dos alunos:

\begin{abstract}
Além de este relacionar-se artisticamente com o mundo e com os outros, o ensino de dança poderia estimular também um relacionar-se crítico do educando com a realidade em que vive. Com isto, estaria proporcionando aos indivíduos relacionamentos artísticos e críticos, permitindo que eles possam compreender as coisas de diferentes maneiras, durante a educação formal [...] adquirirem seu autoconhecimento enquanto vivenciam a corporeidade através de um relacionar-se com o mundo artisticamente (BARRETO, 2004, p. 84).
\end{abstract}

Apesar de estar presente nas mais diversas diretrizes educacionais em todos os níveis de educação, a dança, assim como os outros tipos de arte, segue negligenciada em grande maioria das instituições de ensino regular. Então por que estão essas fora dessas diretrizes? Por falta de conhecimento ou indiferença?

\section{ESPAÇOS DE DANÇA E A MARGINALIDADE DOS SUJEITOS}

Segundo Carlos (1988), o espaço geográfico produz-se em função da reprodução da vida humana e, por outro lado, permite o desenvolvimento da produção capitalista. Dessa forma, podemos dizer que a cidade nasce e se expande à medida que ocorrem fenômenos sociais, culturais e econômicos.

Após as grandes secas (1915, 1932, 1963 e 1979) Fortaleza recebeu um grande contingente de pessoas em busca de oportunidades. A população de Fortaleza em 1900 era 
de 48.369 pessoas, saltando para 78.536 em 1920, 180.185 em 1940 e, em 1980, 1.308.919 (IBGE, 2010).

Os movimentos migratórios intensificados a partir de 1950 estão ligados diretamente aos problemas da economia rural tradicional, principalmente da crise das culturas do algodão, cera de carnaúba, entre outras. Por outro lado, as questões fundiárias e a incidência das secas periódicas que atingem o Ceará, muito têm contribuído para as migrações do campo para as cidades e para a capital (SOUZA, 2006, p. 135).

Fortaleza tem um rápido crescimento populacional na década de 1950, apresentando um crescimento populacional de 49\% m relação à década anterior, e entre os anos de 1970 e 2000 passou de 800 mil habitantes a 2,1 milhões de habitantes (SOUZA, 2006). Esse crescimento desordenado traz graves problemas, como subempregos, exclusão social e desigualdade econômica, agravados pela falta de infraestrutura físico-urbana que atenda a essa população tão complexa e nova, trazendo malefícios graves à sociedade, que se perpetuam e se agravam. Em 2015, Fortaleza figurava como a cidade mais violenta do Brasil e a $12^{\text {a }}$ do mundo (MELLO, 2016). Em 2017, o índice de homicídios foi 96,4\% maior em relação ao ano anterior (DIÓGENES, 2018). Em 2013, os assassinatos de adolescentes na capital tiveram um crescimento vertiginoso, atingindo 141,1 homicídios para 100 mil adolescentes (UNICEF, 2017).

A marginalidade é decorrente da forte segregação socioespacial da urbanização de Fortaleza, pois, segundo Ribeiro (2007) quem está fora do mercado somente tem acesso à moradia à margem da cidade. A violência é um fenômeno recorrente em bairros que não recebem a atenção devida do Estado, pois se há a sua falta, há outras esferas de poder com interesse de impor seu domínio sobre eles. Essa realidade atinge diretamente as crianças e adolescentes. Muitas vezes, esse é o único cotidiano ao qual esses jovens têm acesso, inclusive entrando no cotidiano das escolas. Aliado a isso, há a falta de equipamentos culturais e educativos, o que faz esses jovens verem uma realidade que não propicia um presente e um futuro interessante, com a violência e o descaso social. Segundo Tavares (2009, p. 2):

[...] diante das dificuldades governamentais em solucionar sérios problemas nestas áreas, observou-se um movimento da sociedade em termos de organização para atender a estas questões sociais. Este movimento se intensifica e passa a tomar corpo por volta dos anos 80 e 90 produzindo a consolidação do desenvolvimento e do fortalecimento de associações, entidades filantrópicas e organizações não governamentais sem fins lucrativos (ONGs), que passam a compor o terceiro setor da economia.

Torna-se comum, então, a formação das Organizações Não Governamentais (ONGs), que visam atender essa população mais carente. No caso, pensada pela sociedade civil a 
partir da necessidade de ações que englobem os jovens no contexto cultural. No caso de Fortaleza, as mais comuns são ligadas a esportes e dança, localizadas nos bairros longe do centro, nas margens da cidade.

No meio desse impasse sociológico e geográfico, muito preocupa como todas essas realidades afetam os mais jovens, crianças e adolescentes que, em plena formação social, moral e educacional, muitas vezes têm em caminhos duvidosos exemplos que julgam bons para terem algum futuro e serem protagonistas da construção do seu meio social. Segundo laquinto (2014) os homicídios são a principal causa das mortes de jovens entre 15 e 24 anos, afetando mais os homens, negros, moradores das periferias e de áreas metropolitanas dos centros urbanos.

Os fatos citados têm relação direta com o Índice de Desenvolvimento Humano (IDH), que são números que indicam como renda, educação e longevidade das pessoas. Segundo o Instituto Brasileiro de Geografia e Estatística, o índice de Fortaleza é 0,754, em uma escala de 0 à 1 . Importante lembrar que não é um dado homogêneo, sendo apenas uma média entre todos os bairros, não mostrando as desigualdades sociais entre cada um. Como a própria Prefeitura de Fortaleza (2014) destaca em seu site oficial os bairros Meireles $(0,953)$, Aldeota $(0,867)$, Dionísio Torres $(0,860)$, Mucuripe $(0,793)$, Guararapes $(0,768)$, Cocó $(0,762)$, Praia de Iracema $(0,720)$, Varjota $(0,718)$, Fátima $(0,695)$ e Joaquim Távora $(0,663)$ são os 10 melhores bairros de Fortaleza em desenvolvimento humano. (IBGE, 2010). Segundo Accioly (2009) alguns desses bairros são considerados de elite, e desde a década de 1970 se consolidaram como uma centralidade alternativa, abrigando modernas atividades financeiras e áreas de prioridade dos promotores imobiliários.

Já os piores, segundo Accioly (2009), estão o Conjunto Palmeiras $(0,119)$, que ocupou a última colocação do ranking, seguido de Parque Presidente Vargas $(0,135)$, Canindezinho $(0,136)$, Genibaú $(0,139)$, Siqueira $(0,149)$, Praia do Futuro II $(0,168)$, Planalto Ayrton Senna $(0,168)$, Granja Lisboa $(0,170)$, Jangurussu $(0,172)$ e Aeroporto - Base Aérea $(0,177)$. Grande parte desses bairros está localizada na região oeste da cidade, "[...] em que predominam populações de renda média e baixa, mas que já foram incorporadas há mais tempo à malha urbana, a vulnerabilidade gira em torno da média" (ZANELLA et al., 2009, p. 209). 


\section{O Papel Social das ONGs e suas Características}

Organizações não governamentais, mesmo que não houvesse essa terminologia, são tão antigas quanto a própria coexistência de governos constituídos e empresas (OLIVEIRA, 2014). Elas surgem a partir de carências locais das comunidades a partir da iniciativa social. Segundo Tavares (2009, p. 2):

Este movimento se intensifica e passa a tomar corpo por volta dos anos 80 e 90 produzindo a consolidação do desenvolvimento e do fortalecimento de associações, entidades filantrópicas e organizações não governamentais sem fins lucrativos (ONGs), que passam a compor o terceiro setor da economia.

Como o nome sugere, não surgem a por iniciativa do governo, mas sim a partir de uma vontade coletiva, sem fins lucrativos, que arrecada dinheiro a partir de doações (civis e empresariais) usadas para manter as atividades e pagamento de pessoal, sem obtenção de lucros. Só no Ceará, de acordo com o Mapa das Organizações da Sociedade Civil, pertencente ao Instituto de Pesquisa Econômica Aplicada (2018), estão presentes 36.270 instituições, sendo 7.018 em Fortaleza. São configuradas das mais diversas formas: ligadas a instituições religiosas e outras ligadas à cultura popular; usam música, dança, esportes ou literatura como atividades, dentre outros tipos de serviços oferecidos de acordo com a necessidade local.

Esse mapa é elaborado de acordo com a metodologia de estudos nacionais e internacionais, como a que originou a Fundações Privadas e Associações sem Fins Lucrativos no Brasil (FASFIL), pertencente ao IBGE, com colaboração da Associação Brasileira de Organizações Não Governamentais - ABONG e o Grupo de Institutos, Fundações e Empresas - GIFE. A análise efetuada fornece um panorama geral dessas organizações em 2010, abarcando estatísticas sobre seu quantitativo, localização, tempo de existência, porte, atividade desenvolvida, número de empregados e remunerações (IBGE, 2018), usando como base os dados do Cadastro Central de Empresas - CEMPRE, também do IBGE. Também é possível que instituições e civis possam construir o mapa das organizações da Sociedade Civil enviando através de uma plataforma novas informações qualitativas e quantitativas, sendo esse também um mapa colaborativo (INSTITUTO DE PESQUISA ECONÔMICA APLICADA, 2018).

Em Fortaleza, temos uma diversidade de projetos. Dentro dessa diversidade, há um grande número de projetos voltados para o ensino da dança, seja como vetor educativo, artístico, cultural ou esportivo. A saber, podemos elencar alguns deles conforme o quadro a seguir (quadro 1). 


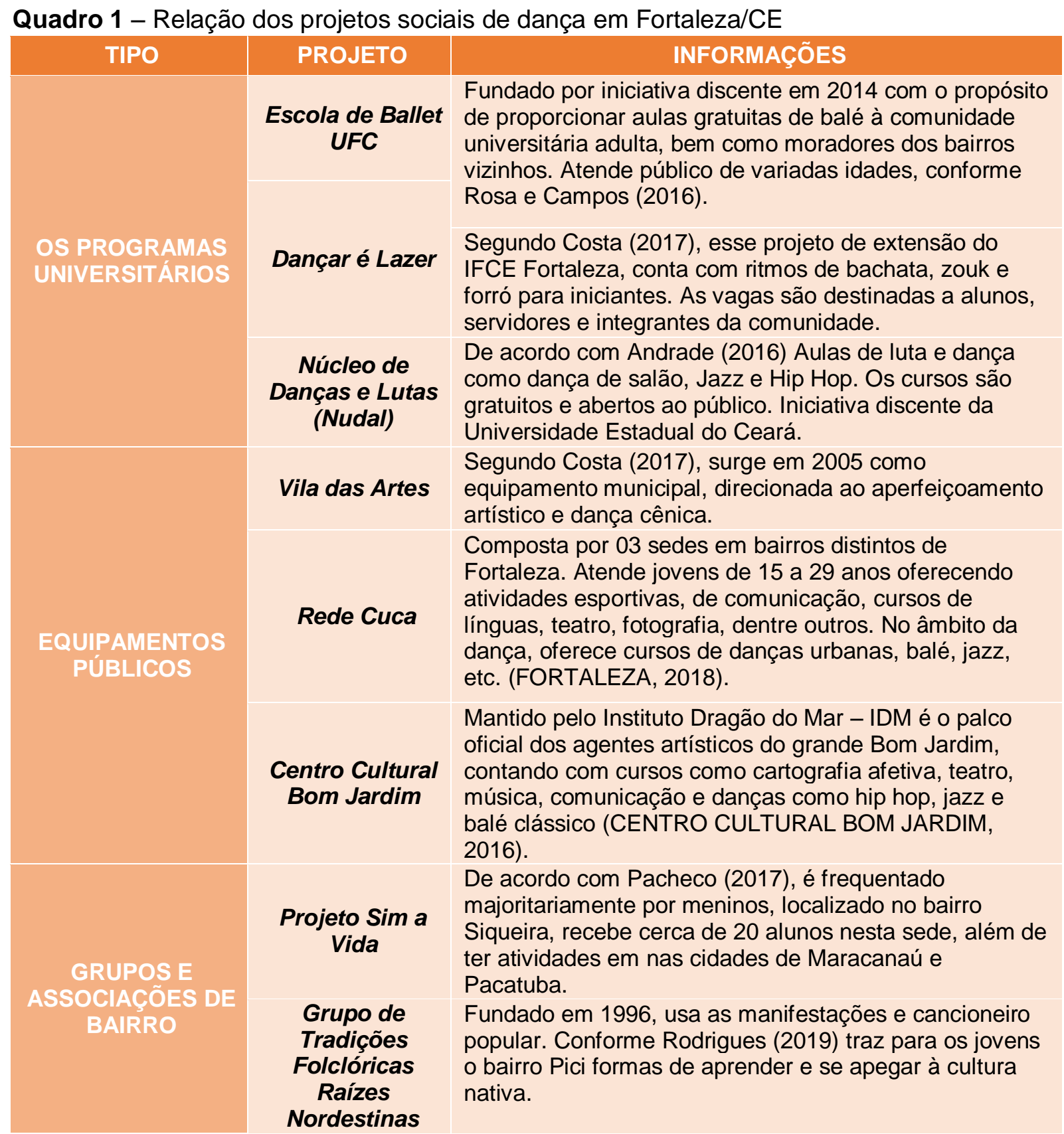

Fonte: Andrade (2016), Centro Cultural Bom Jardim (2016), Costa (2017), Fortaleza (2018), Pacheco (2017), Rodrigues (2019), Rosa e Campos (2016).

Há os que têm sala de dança, professores formados, há os que reutilizam espaços usados para outras atividades esportivas, há os que acontecem em universidades, nas escolas, em associações comunitárias, há os que têm espelhos enormes e os que usam como barra canos de PVC, há os que os alunos têm roupa apropriada e os que vão com roupas improvisadas. Além disso, seus tamanhos e quantidade de pessoas atendidas mudam de acordo com os incentivos, seja da sociedade civil ou de empresas para mantêlas. Há ensino de balé clássico, de danças folclóricas, de zumba, de danças urbanas, de dança de salão e outros diversos tipos de modalidade. 


\title{
Projetos de Dança de Grande Abrangência Social
}

Em Fortaleza, alguns projetos têm mais destaque, seja pela midiatização, pelo porte ou pelo tempo que estão ativos. Essa representatividade se traduz no seu nível de visibilidade e repercussão, seja a nível local ou nacional. No presente trabalho, optamos por dar destaque a três em especial, justamente por terem já um papel social estabelecido e reconhecido, mesmo que em esferas e níveis diferentes, pois as áreas nas quais estão localizados estão em situação de vulnerabilidade social, em que os mais afetados são os mais jovens:

\begin{abstract}
Estar "em situação de risco" é o critério básico para que crianças e adolescentes passem a ser objeto de intervenção dos projetos sociais, seja eles governamentais ou não governamentais, que atualmente elaboram seus discursos e práticas a partir da necessidade de "construir a cidadania" dessas pessoas, ou seja, oferecer-lhes uma socialização específica possibilitando a incorporação de novas disposições dos hábitos, necessárias ao exercício do papel social de cidadão, tendo em vista que a socialização primária, no interior da família ou dos espaços de relações aos quais a origem social lhes permite ter acesso, não foi capaz de lhes fornecer (FREITAS, 2001, p. 70).
\end{abstract}

Os projetos escolhidos são: i) Instituto Katiana Pena; ii) Vidança; e iii) Escola de Dança e Integração Social para Criança e Adolescente (Edisca); respectivamente localizados no bairro Bom Jardim, no bairro Vila Velha e no bairro Parque Manibura.

\section{Instituto Katiana Pena}

Localizado no Grande Bom Jardim, lado oeste de Fortaleza - CE, o instituto foi fundado pela bailarina Katiana Pena, formada pelo também projeto social EDISCA e coreógrafa premiada pelo SATED (Sindicato dos Artistas e Técnicos em Espetáculos de Diversões do Ceará) em 2016 (figura 1). Atende a 550 crianças, jovens e também idosos, oferecendo aula de balé clássico e dança contemporânea. Funciona nos três turnos, com aulas de hora em hora, para que possa atender a toda a demanda.

Katiana, filha de família de 19 filhos, mora no bairro Bom Jardim desde que não havia sinais de urbanização na região, e ela mesma diz "[...] não tinha água, não tinha luz, era muito mato". Conheceu o Circo Escola Respeitável Turma, nascido na década de 1990. Frequentava primeiramente pela refeição que ofereciam; escassa em sua casa. Encantada com os malabarismos resolveu ser artista. No mesmo circo, conheceu a coreógrafa Dora Andrade, que explorava as periferias de Fortaleza em busca de futuros bailarinos para compor seu projeto EDISCA. Mesmo sem fardamento ou dinheiro da passagem, fazia um grande esforço para se dedicar à arte de dançar. 
Figura 1 - Mosaico de fotos do Instituto Katiana Pena no Bairro Bom Jardim

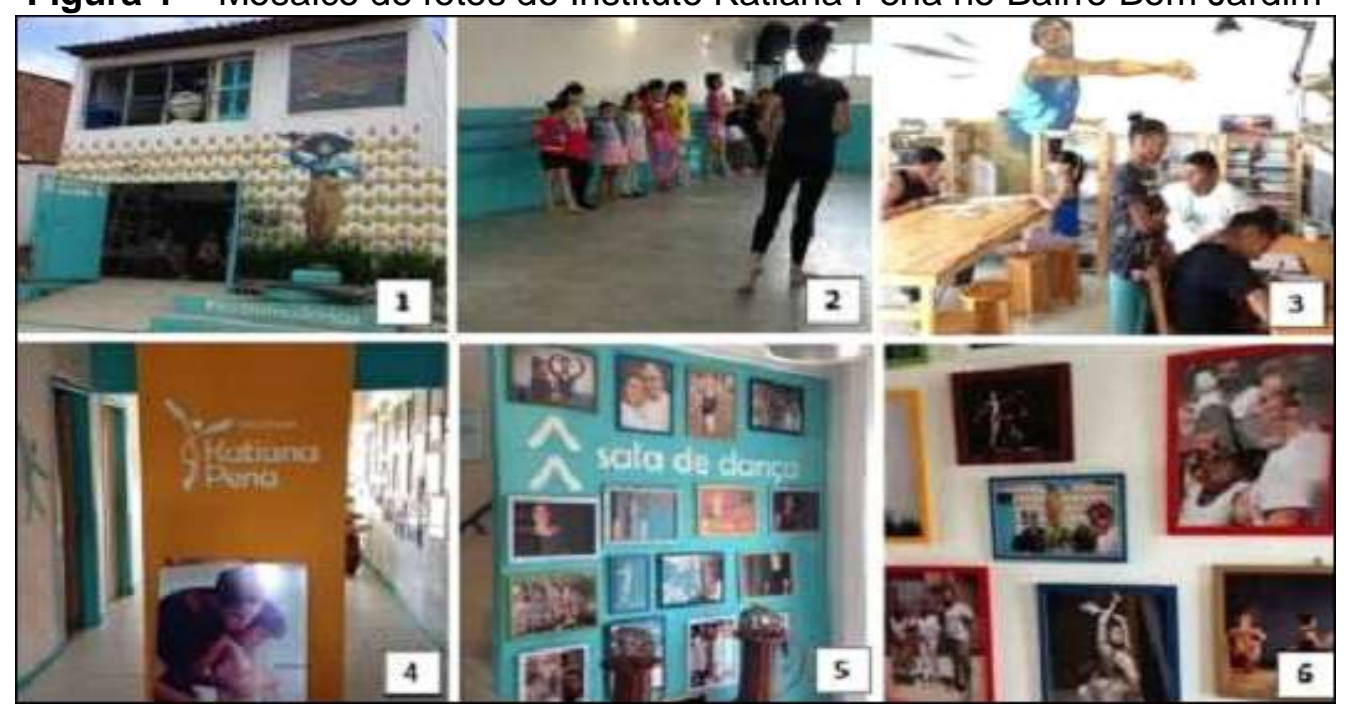

Autoria: Marcos da Silva Rocha (2018).

O projeto surgiu em dezembro de 2005, no CAIC Maria Alves Carioca, mas depois passou a funcionar na própria casa, na qual mora com marido e filho, com o nome Studio de Dança Katiana Pena (SDKP), sob luzes de postes e som emprestado, com a ajuda de familiares, comerciantes locais, com o corpo docente formado por alunos e companheiros de espetáculos e qualquer quantia que os alunos pudessem pagar, ou não.

Em 2017, o lugar onde funciona o projeto foi reformado pelo programa Caldeirão do Huck (Rede Globo), podendo assim aumentar sua demanda de alunos, que passou de 120 para 550 pessoas, vindos de diversas áreas de Fortaleza, incluindo crianças vindas de Caucaia e outras cidades da região metropolitana. As crianças passam por seleção, devem estar devidamente matriculadas na escola e terem frequência assídua no projeto.

O principal palco do projeto é o Centro Cultural do Bom Jardim, que surgiu em 2006, promovendo arte e cultura para os moradores do bairro e imediações. Conta com um corpo de baile chamado "Corpo MuDança", que também nomeia a sala de dança (imagens 2 e 5 do mosaico), e se apresenta em espetáculos pela cidade e também fora dele. No ano de 2018 montaram um espetáculo chamado "A Rua é Nóiz" (imagem 3), retratando o cotidiano das ruas do Bom Jardim, a cultura negra, a resistência LGBT e problemas sociais no palco, representados em forma de arte.

A temporada de 2018, no Teatro José de Alencar, teve a participação de llya Vladimirov e Valeryia Shikina, do corpo de baile do Ballet Bolshoi de Moscou, em um Grand Pas de Deux de Dom Quixote. Também se apresentaram em festivais, eventos universitários e shoppings da capital. O espetáculo traduz o que o instituto se propõe a fazer: trazer o clássico, com sua postura, higiene e arte do balé, mas usando a arte também 
produzida pela comunidade, com coreografias próprias que fogem da rigidez clássica, trazendo a dinamicidade urbana e social local.

\section{Associação Vidança Cia. de Dança do Ceará}

A Associação Vidança Companhia de Dança do Ceará localiza-se bairro Vila Velha, também em Fortaleza - CE, na parte noroeste, quase limite com Caucaia, cidade pertencente à região metropolitana de Fortaleza (figura 2). Surge em 1981, pela iniciativa da bailarina e coreógrafa Anália Timbó, na época integrante da Escola de Dança SESI, iniciativa pioneira de ensino da dança para classes populares, em 1979. Segundo o site oficial da associação, a missão é "Trabalhar com classes populares, priorizando ações formativas em arte, voltadas para crianças e adolescentes em situação de risco e exclusão social" e o objetivo "Proporcionar o estudo da Dança como linguagem e possibilidade expressiva e profissional a crianças e adolescentes do Bairro da Vila Velha" (VIDANÇA, 2016).

Figura 2 - Mosaico de fotos da Associação Vidança Cia. de Dança do Ceará no bairro Vila Velha

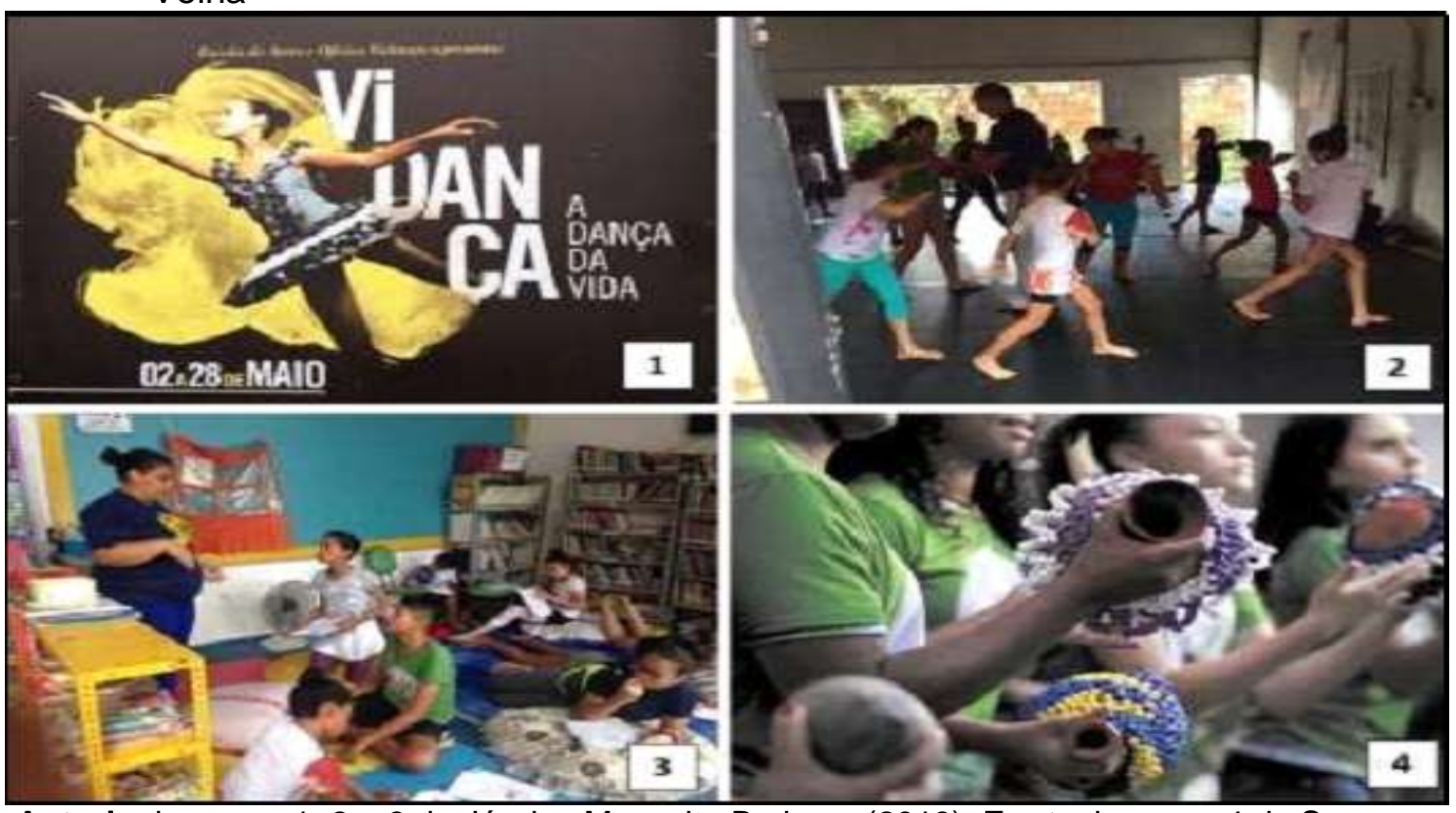

Autoria: imagens 1, 2 e 3 de Jéssica Mesquita Barbosa (2018). Fonte: imagem 4 de Sousa (2018).

A oficina de percussão é voltada para as meninas do bairro, e tem como objetivo dar visibilidade e protagonismo a elas, chamada de Tambatuque das Marias (imagem 4 do mosaico). Os instrumentos são construídos pelas próprias participantes visando instigar as práticas de autonomia, coletividade e sustentabilidade. 
O objetivo que diferencia este projeto do Tambatuque do Vidança, é o recorte de gênero. Por acolhermos um número mais expressivo de meninas e entendermos as problemáticas de gênero que perpassam a vida da mulher, fez-se oportuno desenvolver o empoderamento destas alunas de 7 a 21 anos por meio da música percussiva (VIDANÇA, 2018).

Importante também se lembrar do cortejo literário, no qual as crianças atendidas, de 15 em 15 dias, saem pelas ruas e escolas do bairro Vila Velha, levando música, percussão, dança e literatura em forma de ciranda. Essa é a forma encontrada pelo projeto de levar efetivamente a arte para os moradores do bairro, além de ser uma vitrine para aumentar o raio de divulgação do projeto para mais crianças e adolescentes da comunidade.

A associação é dividida em subprojetos, e cada um recebe apoio e capta recursos de diversas fontes. Por exemplo, o Tambatuque das Maria recebe financiamento do "Criança Esperança" e Secretaria de Cultura do Estado (SECULT). O projeto, como um todo, recebe apoio de empresas como ENEL, M. Dias Branco e - Cegás - Companhia de Gás do Ceará (2018).

\section{Escola de Dança e Integração Social para Criança e Adolescente (EDISCA)}

A EDSICA foi fundada, em 1991, pela coreógrafa e bailarina Dora Andrade, em busca de levar arte e proporcionar atividades educacionais para os jovens das periferias de Fortaleza (figura 3). Para além da dança, a escola pretende ensinar o que seria "ser cidadão", levando em consideração que, antes de tudo, é necessário ter acesso à condições básicas de saúde, educação e assistência, que muitas vezes são deficientes para esses jovens, tendo em vista as condições sociais aos quais são expostos nas periferias onde moram. Um dos cuidados principais que a escola tem com seus alunos, desde sua chegada, é com a higiene, ganhando kits de higiene corporal. A alimentação também é regrada para manter a boa forma e proporcionar bom condicionamento físico aos bailarinos. Em entrevista ao Jornal O POVO, Dora Andrade (2018) cita quais outras atividades são promovidas na instituição e oferece:

[...] aulas de português, de matemática, refeição, grupos de convivência com psicólogos, onde eles discutem direito, cidadania, afetividade, enfim, temas transversais. Temos uma biblioteca com mais de 5.000 títulos, e há um esforço da área pedagógica para ampliar o gosto dessas crianças pela leitura. Temos, dentro da área de fortalecimento à escola informal, parcerias com escolas privadas de alta qualidade.

Apontada como um exemplo nacional de projeto social a ser seguido, pela imprensa e população, têm diversos prêmios concedidos por instituições públicas e privadas, como Prêmio Abrinq pelos Direitos da Criança (1997), Prêmio UNESCO "Juventude e Cidadania" 
(1999) e Prêmio "Sereia de Ouro" (2000). Também é reconhecida internacionalmente, principalmente por suas apresentações na Alemanha, Áustria, França e EUA, além de contar com inúmeros trabalhos acadêmicos e reportagens que propagam sua relevância social dentro e fora do país.

Figura 3 - Mosaico de fotos da EDISCA, localizada no bairro Parque Manibura

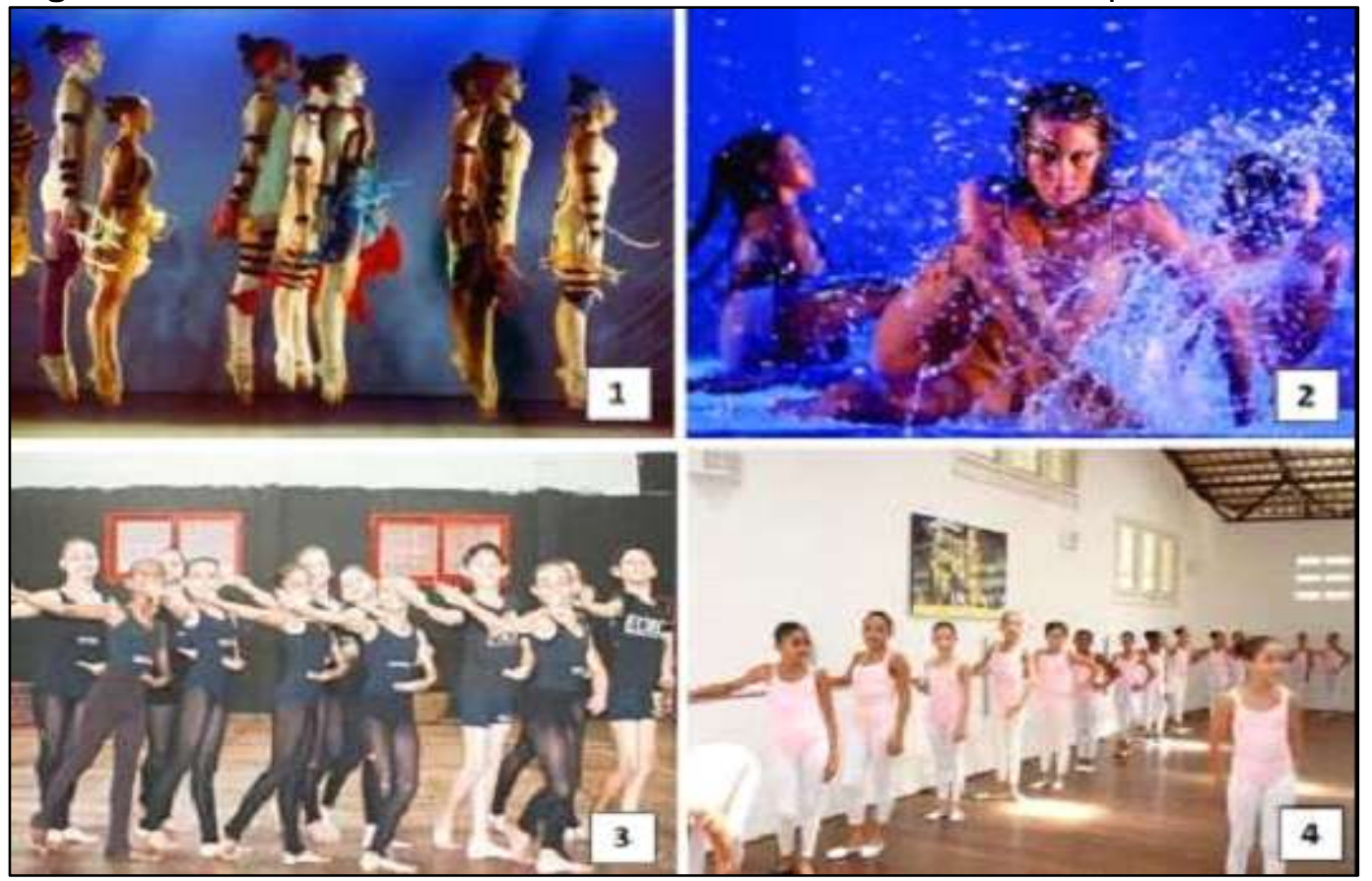

Fonte: imagens 1 e 2 de Petrillo, (2011); imagem 3 e 4 de Viegas (2017).

Quem constrói a EDISCA são crianças e jovens dos bairros com índices de vulnerabilidade social, das regionais I, II, III e IV, com idades entre sete e 12 anos e sem experiência em dança. Também são recebidos os jovens e jovens de 13 a 17 anos, com ao menos dois anos experiência de dança, ambos sendo comprovadamente de baixa renda.

\section{A DANÇA COMO VETOR EDUCATIVO DE RESISTÊNCIA}

Quando perguntado aos integrantes desses projetos quais são os principais problemas nos bairros onde estão inseridos, muito se fala das atuações das facções criminosas, pois mesmo que os alunos não estejam inseridos nelas, é uma realidade da qual eles fazem parte, seja por uma ação violenta perto de casa ou algum parente ou amigo que seja integrante. Muitas vezes, só por morar na periferia, acabam sendo estigmatizados como um deles. Infelizmente, essa é uma situação em que muitos entram com promessas de ter algo a mais na vida e não tem um final feliz.

O estigma do adolescente negro e favelado ser necessariamente criminoso é agravado pela mídia sensacionalista que sempre mostra a periferia pelo lado da 
criminalidade no qual está inserida, não mostrando as outras possibilidades que existem na sua comunidade que, no caso, podem ser justamente os projetos sociais de dança que estão sendo citados nesse trabalho.

Podemos perceber que a dança é usada como uma maneira de sair de realidades difíceis nas quais crianças e jovens é exposta todos os dias. $\mathrm{Na}$ mesma entrevista da Kimberly, cuja frase começou este trabalho, quando a pergunta foi o que não gostava no seu bairro, ela respondeu "Quando solta tiro aqui, as vezes tem". Mas quando a pergunta foi sobre o que mais gostava, ela fala "Aqui do Katiana (Instituto Katiana Pena)". Na fala dela, juntamente com seu sorriso ao responder, podemos perceber esse espaço como um lugar diferenciado onde ela e outras crianças têm possibilidades além do que a sociedade espera de uma criança da periferia.

A dança traz consigo, quase sempre, um sentimento de rebeldia, e consequentemente, estimula invenções e propostas de coisas novas. Estas características que ela revela são manifestações dos descontentamentos e das insatisfações das pessoas diante da vida. Dançar como forma de lazer, celebrar ou fazer arte pode representar formas de tornar a vida mais leve e repleta de prazer (BARRETO, 2004, p. 79).

Esta citação nos faz lembrar a Gabriela, de 10 anos, quando ela responde sobre o que mais gosta de fazer no instituto: "Gosto mais de fazer salto e giros". Que seus giros sejam iguais Shiva que, com seus movimentos, destrói e constrói novos mundos próprios e que seus saltos a levem para todos os lugares que o compõem, fazendo assim vários mundos melhores em uma realidade que não propicia condições para sonhar. Que todos esses projetos continuem permitindo que esses jovens encontrem na arte uma nova maneira de perceber o mundo e de se sentirem capazes de construir uma sociedade menos angustiada e lesionada.

\section{A PERIFERIA DANÇA: CONCLUSÕES DE UMA GEOGRAFIA BAILARINA}

"Às vezes o pessoal da rua fica apresentando dança, tem festinha". Esta é a resposta de Gabriela, de 10 anos, aluna assistida por um dos projetos, quando perguntada sobre o que ela mais gosta no seu bairro (Bom jardim). Seguindo uma perspectiva cultural, fenomenológica e humanista em geografia, esta resposta nos faz refletir sobre qual a concepção de bairro que essas crianças têm, mais precisamente, nos leva a pensar sobre quais mundos elas imaginam e (re)criam para poder viver. Porém se levarmos para o contexto social dos projetos, é possível perceber que cada projeto cria seu próprio mundo, cada um tem o seu Shiva, e se distancia e se recolhe da realidade de desigualdade social no qual estão inseridos. 
Um mundo pode ser apenas uma casa, um pequeno espaço... Mas para um bailarino, qualquer espaço torna-se um lugar para dançar. Dançar é enfrentar forças gravitacionais, dores musculares ou também uma forma de fugir de uma realidade cruel.

A arte é nada mais do que a arte! Ela é a grande possibilitadora da vida, a grande aliciadora da vida, o grande estimulante da vida... A arte como a redenção do que conhece - daquele que vê o caráter problemático da existência, que quer vê-lo, do conhecedor trágico. A arte como redenção do que age - daquele que não somente vê o caráter terrível e problemático da existência, mas o vive, quer vive-lo, do guerreiro trágico, do herói (NIETZSCHE, 1999, p. 50).

Como pesquisadores, é importante seguir métodos e regras científicas, utilizando-se dos conceitos geográficos. Mas, como bailarino, o importante é efetuar movimentos de acordo uma coreografia, utilizando precisão, mas também sentimentos. Então por que não fazer a junção das duas? A geografia como estudo do espaço se torna muito pertinente para o estudo da dança, tendo as mais diversas possibilidades, de projetos sociais e de corporeidade. Uma geografia significativa se faz quando uma pesquisa é feita com olhares mais atentos e sensíveis sobre ações que realmente têm uma efetividade sobre a sociedade.

Os projetos sociais de dança surgem justamente com o objetivo de modificar uma realidade adversa ao bem-estar social, transformando caminhos que, segundo uma condição sociocultural, estariam à margem da sociedade em todos os âmbitos. Nesses lugares, é possível encontrar meio de exercer uma cidadania e construir seus próprios mundos, além de expandi-los para toda uma comunidade.

\section{REFERÊNCIAS}

ACCIOLY, V. M. A metrópole e o impacto das políticas públicas na expansão urbana: Fortaleza entre 1980 e 2008. In: ENCONTRO DE GEÓGRAFOS DA AMÉRICA LATINA EGAL, 12., 2009, Montevideo, UY. Anais [...].Montevideo, UY: Observatório Geográfico da América Latina, 2009. p. $1-20$.

ANDRADE, D. Dois dedos de prosa com Dora Andrade. [Entrevista cedida a] O POVO online, Fortaleza, CE, 21 jan. 2018. Disponível em: https://bit.ly/2JkZUSv. Acesso em: 19 maio 2018.

ANDRADE, V. Nudal/Uece oferece aulas gratuitas de lutas e danças. O POVO online, Fortaleza, 11 maio 2016. Disponível em: http://twixar.me/rr11. Acesso em: 8 jul. 2019.

BARRETO, D. Dança...: ensino, sentidos e possibilidades na escola. Campinas, SP: Autores Associados, 2004.

BRASIL. Ministério da Educação e do Desporto. Secretaria de Educação Fundamental.

Parâmetros curriculares nacionais. Brasília, DF: MEC/SEF, 1998. 
BRASIL. Presidência da República. Lei № 9.394, de 20 de dezembro de 1996. Estabelece as diretrizes e bases da educação nacional. Brasília, DF: Congresso Nacional, 1996. Disponível em: https://goo.gl/x3Lxoi. Acesso em: 5 jun. 2018.

CARLOS, A. F. A. Espaço e indústria. São Paulo: Contexto, 1988.

CENTRO CULTURAL BOM JARDIM - CCBJ. 2016. Disponível em: https://goo.gl/9oL3BS. Acesso em: 25 maio 2018.

COMPANHIA DE GÁS DO CEARÁ - CEGÁS. Vidança, a dança da vida. mam.bo, 21 mar. 2018. http://www.cegas.com.br/socio-ambiental/vidanca-a-danca-da-vida/. Acesso em: 27 abr. 2018.

COSTA, M. Passos livres. O POVo online, Fortaleza, CE, mar. 2017. Disponível em: http://twixar.me/9xm. Acesso em: 11 jul. 2019.

DARDEL, E. O homem e a Terra: natureza da realidade geográfica. São Paulo:

Perspectiva, 2015.

DIÓGENES, J. CE teve recorde de homicídios em 2017; em Fortaleza, aumento foi de 96,4\% em um ano. Estadão, São Paulo, 27 jan. 2018. Disponível em: encurtador.com.br/KPQZ0. Acesso em: 8 jul. 2019.

FORTALEZA. Prefeitura Municipal. Prefeitura apresenta estudo sobre desenvolvimento humano por bairro. Notícias, Fortaleza, CE, 20 fev. 2014. Economia. Disponível em: encurtador.com.br/lmqtO. Acesso em: 8 jul. 2019.

FORTALEZA. Prefeitura Municipal. Rede Cuca. Disponível em: https://bit.ly/2g5x6xc. Acesso em: 11 maio 2018.

FREITAS, I. C. M. de. Arte e cidadania numa experiência pedagógica com crianças e adolescentes da periferia de Fortaleza. Revista de Ciências Sociais, Fortaleza, v. 32, n.1/2, p. 69-76, 2001. Disponível em: https://goo.gl/uVvzG1. Acesso em: 27 abr. 2018.

IAQUINTO, K. Efeito dominó: o custo da violência. Revista Conjuntura Econômica, Rio de Janeiro, RJ, v. 68, n. 1, p. 20-27, jan. 2014. Disponível em: https://bit.ly/2JcVSw3. Acesso em: 6 abr. 2018.

IBGE. Brasil em síntese: Brasil / Ceará / Fortaleza. Sinopse do senso demográfico brasileiro 2010. Fortaleza, CE: IBGE, 2010. Disponível em: http://twixar.me/8r11. Acesso em: 8 jul. 2019.

IBGE. Panorama geral: Fortaleza. Fortaleza, CE: IBGE, 2018. Disponível em: https://goo.gl/42uxoC. Acesso em: 1 maio 2018.

INSTITUTO DE PESQUISA ECONÔMICA APLICADA - IPEA. Mapa das organizações da sociedade civil. Disponível em: ttps://bit.ly/2sIUvtV. Acesso em: 6 maio 2018.

LOPES, A. S.; BARROS, A. A imagem simbólica na dança. Pesquisa em Debate, São Paulo, n. 3, p. 35-39, 2006. Disponível em: encurtador.com.br/afGN0. Acesso em: 10 jun. 2019.

MELLO, J. 21 cidades brasileiras estão entre as 50 mais violentas do mundo. Jornal GGN: O Jornal de Todos os Brasis, São Paulo, SP, 27 jan. 2016. Segurança pública. Disponível em: http://twixar.me/txm1. Acesso em: 11 jul. 2019.

MIRANDA, R. Corpo-espaço: aspectos de uma geofilosofia do movimento. Rio de Janeiro: 7Letras, 2008.

NIETZSCHE, F. Obras incompletas. São Paulo: Nova Cultural, 1999. (Os pensadores).

OLIVEIRA, L. Entre o público e o privado. In: INSTITUTO DE PESQUISA ECONÔMICA PEA. Revista Desafios do Desenvolvimento, Brasília, DF, ano 10, n. 79, p. 57-60, 2014. Disponível em: https://bit.ly/2LXi5Mf. Acesso em: 5 abr. 2018. 
PACHECO, L. Projeto no Siqueira ensina Ballet Clássico a meninos. O POVO online, Fortaleza, 8 nov. 2017. Disponível em: https://bit.ly/2J4CXn0. Acesso em: 12 maio 2018.

PETRILLO, M. Sagrada: 2011. Fortaleza, CE: EDISCA, 2011. Disponível em: http://edisca.org.br/portfolio-item/sagrada-2011/. Acesso em: 8 jul. 2019.

QUEIROZ FILHO, A. C. Corporema: por uma geografia bailarina. Vitória, ES: Antonio Carlos Queiroz Filho, 2018.

RIBEIRO, L. C. Q. Desafios da construção da cidadania na metrópole brasileira. Sociedade e Estado, Brasília, DF, v. 22, n. 3, p. 525-544. set./dez. 2007. Disponível em: goo.gl/HSvZvr/. Acesso em: 3 jun. 2018.

RODRIGUES, R. S. Mapa cultural do Ceará. Grupo de Tradições Folclóricas Raízes Nordestinas. Disponível em: encurtador.com.br/coKP6. Acesso em: 8 jul. 2019.

ROSA, D. M.; CAMPOS, M. A. A. Escola de Ballet da UFC. Revista Encontros Universitários da UFC, Fortaleza, v. 1, n. 1, p. 4778, 2016. Disponível em: http://twixar.me/br11. Acesso em: 8 jul. 2019.

SANTOS, M. Metamorfoses do espaço habitado: fundamentos teórico e metodológico da geografia. São Paulo: Hucitec, 1988.

SILVA, J. M. O.; LOPES, R. L. M.; DINIZ, N. M. F. Fenomenologia. Revista Brasileira de Enfermagem, Brasília, DF, v. 61, n. 2, p. 254-257, 2008. Disponível em: https://bit.ly/2LkEstQ. Acesso em: 20 maio 2018.

SOUSA, R. O batuque delas. Diário do Nordeste, Fortaleza - CE, 28 mar. 2018. Disponível em: goo.gl/Z6bgMk. Acesso em: 25 maio 2018

SOUZA, M. S. Segregação socioespacial em Fortaleza. In: SILVA, J. B.; DANTAS, E. W. C.; ZANELLA, M. E.; MEIRELES, A. J. (org.). Litoral e sertão: natureza e sociedade no Nordeste brasileiro. Fortaleza, CE: Expressão Gráfica, 2006.

TAVARES, M. Análise de projetos sociais: caminho para melhorar o ensino. [Entrevista cedida a] Folha Dirigida. Difusão de Idéias, São Paulo, SP, p. 1-4, out. 2009. Disponível em: https://bit.ly/2sAPTWT. Acesso em: 3 jun. 2018.

UNICEF. Fundo das Nações Unidas para Infância. Brasil. Trajetórias interrompidas: homicídios na adolescência em Fortaleza e em seis municípios do Ceará. UNICEF: Fortaleza, CE, 2017. Disponível em: http://twixar.me/xrVn. Acesso em: 10 jun. 2019.

VIDANÇA. Associação. Expandindo criações, impulsionando sonhos. Fortaleza, CE: Vidança, 2016. Disponível em: goo.gl/fPe3Ae. Acesso em: 27 abr. 2018.

VIDANÇA. Programas. Tambatuque das Marias (Criança Esperança). Crianças.

Fortaleza, CE: Vidança, 2018. Disponível em:

https://www.vidanca.org.br/projetos/tambatuque-das-marias-crianca-esperanca. Acesso em: 27 abr. 2018.

VIEGAS, L. Edisca abre loja: estrelário com linha de produtos exclusivos. Penteadeira Amarela, Fortaleza, CE, 6 nov. 2017. Disponível em: https://bit.ly/2sywUfE. Acesso em: 31 maio 2018.

ZANELLA, M. E.; COSTA, M. C. L.; PANIZZA, A. C.; VIEIRA, S. R. Vulnerabilidade socioambiental de Fortaleza. In: COSTA, M. C. L.; DANTAS, E. W. C. (org.).

Vulnerabilidade socio ambiental na região metropolitana de Fortaleza. Fortaleza, CE: Universidade Federal do Ceará, 2009.

Recebido: março de 2019. Aceito: julho de 2019. 